\title{
Study on control strategies of gas power station
}

\author{
Li Ying ${ }^{1}$ \&Yang Xiju ${ }^{2}$ \& Liu Xiaobo² \&Long Xianzhong ${ }^{2}$ \\ ${ }^{1}$ Liupanshui Power Supply Bureau, Liupanshui, GuiZhou, China \\ ${ }^{2}$ School of Electrical Engineering GuiZhou University, Guiyang, GuiZhou, China
}

KEYWORD: power grid; strategy of gas power station; communication; synchronous generator; grid connected inverter

ABSTRACT: The Chinese economy is developing rapidly, the demand for energy is getting more and more intense. With the development of coal mine, the utilization of gas is getting more and more important, and the numerous gas generating units will be connected to the power grid. Due to the characteristics that the unit capacity of gas generator is small, the gas safety requirements is high, and gas power stations is sensitive to grid disturbances, gas power stations which are connected to distribution network will produce a correspond impact on the grid. Therefore, it is important to study the control strategy of gas power station. In view of three kinds of operation modes of gas power generation stations in China, the island and anti-island effect of the distributed gas power stations connected to distribution network are discussed. Then the three kinds of anti-Island efficiency strategies are proposed for gas power generation, which are based on communication, synchronous generator and grid connected inverter, and their advantages and disadvantages are analyzed and compared. The three kinds of anti-Island benefit strategy have important reference and guidance for the design and operation of gas power stations in China.

\section{The model of mine gas generator}

Ignore the rectifier loss and assume the output electromagnetic power of the rectifier equal to the magneto alternator. Based on the relation of rotate speed and power, the output electromagnetic torque of the generator $M_{e}$ :

$$
M_{e}=\frac{P_{e}}{\omega}=K_{e} I_{d}-\mathrm{K}_{\mathrm{x}} I_{d 2}
$$

Ignore the damping of the generator, the rotor motion formation of the generator:

$$
\frac{d \omega}{d t}=\frac{1}{J}\left(M_{m}-M_{e}\right)
$$

Therefore the simplified model integrates magneto alternator and rectifier is shown in Figure.1.

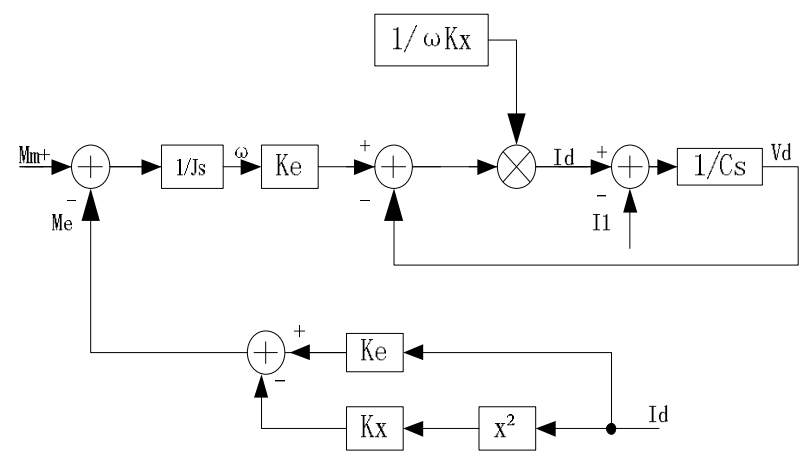

Figure. 1 The simplified model integrates magneto alternator and rectifier 


\section{The operation strategies of gas generating units}

At present, the capacity of the gas engine generator unit is small and the common single unit capacity is $500 \mathrm{~kW}$. It needs more than one such set at the same time operation in the gas power station. Due to the fact that the gas content under the mine is changed with the seasons and the temperature, the power generating unit could be put into full load operation when air volume is enough; and some of the generators should be stopped or the generators should be reduced to ensure the operation of the unit is more efficient when it is insufficient. This involves the operation of the generator sets. Of course, it needs to use some appropriate algorithms to find a more economical operation mode, with taking the economic operation of the units into account and according to the specific conditions.

\section{The operation mode of gas generating units}

The gas generating unit can be operated in the following three ways(Pei Wei et al. 2008):

1) Low voltage transmission: The output voltage of the gas generating unit is 400 volts, which directly supplied the power to the mining area. But it can only form a separate low-voltage power supply network, for the power supply distance can not be too far.

2) High voltage transmission: The output voltage of gas generator is supplied power for a remote mining area by a boost for $6 \mathrm{kV}$, but it needs the step-up and step-down substation equipments, to form a network structure with the generate electricity - step-up - transmission- step-down -the electric equipments.

3) Boost and connected grid to supply power: The output voltage of the gas generating units connected with the power distribution network of the mining area is $6 \mathrm{kV}$ or $10 \mathrm{kV}$.On the normal condition, the gas generators transmit power to the power grid, or they will be a user of the power grid when gas generators do not work.

\section{Island operation mode}

The first two operation modes both are isolated island operation modes in three kinds of operation modes of coal mine gas generating units (Kim et al. 2010) . The system power supply is interrupted and the security and reliability of power supply of the user can not be guaranteed when the generator sets are in the station of maintenance or failure. The latter operation mode can ensure the uninterrupted power supply of the electric equipments in the mine area. But due to the instability of the gas volume and the concentration, operating characteristics of gas turbine and operation of conventional power plant is different, it will cause the influence for mine distribution network power supply reliability, grid operation, distribution network operation and management after grid, which endanger the safety of mine distribution network. On the other hand, due to the low voltage of the gas power station connected to grid, the power grid fluctuations can easily cuase the gas power stations to be taken off the network and then form the island system. The reasonable operation level of voltage and frequency can not be guaranteed when the island system is not stable, it will lead to the full power cut in gas power station, and then damage the generators.

The island effects can be divided into two kinds, the anti-islanding and utilization of islanding(Hou Chaoyong et al. 2011). When power main grid trips, the operation of unscheduled distributed gas stations devices will cause losses to users and power distribution equipments. Therefore, the gas station devices in power grid need the function of anti-islanding protection, so that we can immediately stop running and have time to detect islanding. Gas stations, usually connect to low voltage spare feeder, whose power are smaller. Grid-connected inverter can form the islanding with individual load. However, the untreated grid-connected inverter, can integrate the detection and control islanding function in its control strategies, so the gas stations' anti-islanding strategy can only be aimed at the grid-connected inverter.

\section{The strategy of anti-islanding}

\section{The strategy of anti-islanding based on communication}

The strategy of anti-islanding is based on communication, detecting islanding by wireless communication; the strategy of local anti-islanding adopts the active strategy. The strategy monitors the var- 
iation of the voltage, frequency and the corresponding impedance in control system by adding the disturbance signal, to determine whether the power grid is exist(Katiraei et al. 2006).

(1)The cascading trip strategy

The main idea of the cascading trip strategy is to monitor the condition of all the circuit breakers or automatic switches, which may lead to the islanding. When a switch action, and then substation separates in the gas station system, the central control unit will confirm island area, and immediately send a signal to terminate the running of power devices in the island area.

In some way, this solution can be simplified, if a single gas generating device connects to a substation with fixed topological structure by a limited number of automatic switches(Wai et al. 2013). The status signals can be directly sent to the gas generating devices from each monitoring point, without the central control unit. However, cascading trips strategy may be complex, if there are changes for multiple automatic switches and feeder topology in system.

Under changing of topological structure, the cascading trip strategy must adopt central control unit to ensure the execution reliability, and the central control unit needs the latest information of topological structure. This strategy requires a lot of communication, in order to make it more reliable, radio signal must be continuously sent to the devices or the central control unit, because the interruption of a signal can be regarded as the related circuit breakers or automatic switches jump to open.

(2)The power line carrier communication strategy

This strategy is to send the signal by the electric power line (Vandoorn et al. 2011). Transmitter constantly sends signals to all gas generating devices. All gas power generation devices is equipped with signal detector, if the detector is not received signal, the state is islanding running, and gas power generation device will be terminated immediately. Signal transmitter has a small amount of auxiliary input, any one without sending signal, will lead to all the power generation device trip in system. This feature is very effective to islanding detection occurred in the transmission system. It is nothing to do with the feeder topological structure, very easy to implement. And the output signal does not affect the normal operation of the system, and not have bad effect on the power quality and system transient. But at the same time, there are two things need to note, one is a cost factor, signal generator is a medium voltage device that requires step-down transformer to connect, which installed in the power grid; two is carrier signal may cause interference to other power line communication.

\section{Anti Island strategy based on synchronous generator}

The local anti-Island strategy is based on the type of gas generating device, which main is the active strategy of anti-island strategy in the method of the synchronous generator (Rosa et al. 2009). The active strategy detects the island effect through the system response, which is got by adding the disturbance to the power grid. Active anti-island strategies and gas generation device have a corresponding link. For synchronous generator, the choice of injection parameters will be limited, due to the generator's high voltage and that the generator is not easy to control. The following are two types of active anti-island strategies for synchronous generators.

(1)Impedance measurement strategy

The principle of measuring impedance is that the impedance value is got in the output side of the synchronous generator. When the generator is connected to the power grid, the measurement value of the system impedance will be very small; when the power grid trip, the impedance measurement value will rise, so that the island effect can be detected. If we want to get the system impedance of the continuous monitoring, the disturbance needs to be added to the grid.

The obvious advantage of impedance measurement strategy is that the mismatch of power in the isolated island system does not affect the detection performance. The problem is that when there are multiple synchronous generators connected to the system, the grid disturbance may interfere each other, and then the dilution effect occurs, resulting in the strategy is effective affected and the cost will be relatively large. Under the condition that the load may have a frequency response, the disturbance parameter will not affect the measured parameters, and the island effect would not be detected.

(2) The voltage of generator terminal change strategy

The generator terminal voltage variation strategy is a variation of the impedance measurement strategy, it detects island effects through the changes of reactive power current, which are the results of the voltage changes of synchronous generator terminal. Because of the measure impedance of the system are different between the grid connected and islanded operation mode, so the change of synchronous generator's reactive power in the two modes may have very big difference; when the sta- 
tion is connected with a power grid, reactive power has changed very little. As a result, a small voltage change of the automatic voltage regulator of synchronous generator can be determined by monitoring the changes of the output reactive power of synchronous generator to determine the operation of the island. This method is more practical and effective than the direct impedance method, and it is only necessary to change the excitation of synchronous generator.

\section{Anti-island strategy based on grid inverter}

General converter is connected to the low-voltage distribution network. Grid inverter system often uses a local anti-island strategy, meanwhile, it must meet the following requirements:

(1)Following the grid standards ;

(2) The protection function integrated in the grid inverter instead of using protective relay;

(3) Anti-island of grid inverter protection must be tested .

This strategy can be divided into three categories:

(1)The inverter side passive anti-island strategy is judged through abnormal voltage.

(2)By introducing a disturbance signal, the inverter side active anti-island strategy detects the changes of the corresponding network parameters to determine the status.

(3)To ensure that the frequency and voltage does not exceed the normal operating range and avoid damaging user equipments, the grid side passive strategy adopted frequency and voltage protection. For the distributed gas power stations with high power levels, the frequency and voltage relay are required.

Impedance insert strategy is setting up a low impedance component in the area which is easy generate a lonely island effect in the grid. The low impedance component often is the installed capacitor

group. When the grid side switch, after a little time delay, the inserted switch is closed, then capacitor group is inserted. If power tripping lead to the local load and the output power of inverter to be coordinated, then the added large capacitance will result in an imbalance of energy balance. Then the frequency protection device will finally be triggered by the sudden drop in the frequency and the mutation of the current and voltage phase.

The advantage of the impedance insert strategy is that it only has a time delay between power grid tripping and inserting capacitance group, to ensure that the capacitor's insertion will not break the power balance. And the capacitor group is easier to get, at the same time, it also can undertake reactive power compensation. The disadvantage of the impedance insert strategy is that the investment cost of capacitor group is high, so adopt this strategy is not economic.

\section{conclusion}

This paper expounds the operation modes of gas station. The island effect and anti-island effect is discussed after the distributed gas station are connected to grid. Three kinds of anti-Island efficiency strategies are proposed. The first anti-island strategy is based on the communication which includes analysis of the cascading trip and the power line carrier communication. The second anti-island strategy is based on synchronous generator, which introduces the impedance measurement strategy and voltage of generator terminal change strategy. The third anti-island strategy is based on grid inverter, which expounds the conditions and classification when it uses the strategy. Finally introduced impedance insert strategy, and presents its advantages and disadvantages.

\section{REFERENCES}

[1] Hou Chaoyong \& Hu Xuehao \& Hui Dong. 2011. Control strategy of grid-connected converter with LCL filter based on discrete state-space model. Proceedings of the CSEE 31(36):8-15(in Chinese).

[2] Kim J Y \& Jeon J H. 2010. Cooperative control strategy of energy storage system and microsources for stabilizing the microgrid during islanded operation. IEEE Transactions on Energy Conversion 25 (12):3037-3048.

[3] Katiraei F \& Iravani M R. 2006. Power management strategies for a microgrid with multiple distributed generation units.IEEE Transactions on Power Systems 21(4):1821-1831. 
[4] Pei Wei \& Sheng Kun \& Kong Li, et al. 2008. Impact and improvement of distributed generation on distribution network voltage quality. Proceedings of the CSEE 28(13):152-157(in Chinese).

[5] Rosa A \& Mastromauro \& Marco Liserre \& Tamas Kerekes. 2009. A Single-Phase VoltageControlled Grid-Connected Photovoltaic System With Power Quality Conditioner Functionality. IEEE Transactions on Industrial Electronics 56(11): 4436-4444.

[6] Vandoorn T L \& Renders B \& Degroote L, et al. 2011. Active load control in islanded microgrids based on the grid voltage. IEEE Transactions on Smart Grid 2(1): 139-151.

[7] Wai R J \& Lin C Y \& Huang Y C, et al. 2013. Design of high-performance stand-alone and gridconnected inverter for distributed generation applications. IEEE Transactions on Industrial Electronics 60(4): 1542-1555. 